\title{
pH dependent mechanisms of hydrolysis of 4-nitrophenyl $\beta$-D-glucoside
}

Amani Alhifthi and Spencer J. Williams*

School of Chemistry and Bio21 Molecular Science and Biotechnology Institute, University of Melbourne, Parkville 3010, Victoria, Australia

\section{sjwill@unimelb.edu.au}

Keywords:

Abstract. 1,2-trans-Glycosides hydrolyze through a range of mechanisms under conditions of different $\mathrm{pH}$, but systematic studies are lacking. Here we report the $\mathrm{pH}$-rate constant profile for the hydrolysis of 4-nitrophenyl $\beta$-D-glucoside. An inverse kinetic isotope effect $\left(k\left(\mathrm{H}_{3} \mathrm{O}^{+}\right) / k\left(\mathrm{D}_{3} \mathrm{O}^{+}\right)=0.63\right)$ in the acidic region indicates that the mechanism requires the formation of the conjugate acid of the substrate for the reaction to proceed, with heterolytic cleavage of the glycosidic $\mathrm{C}-\mathrm{O}$ bond. Reactions in the $\mathrm{pH}$-independent region extrapolated to zero buffer concentration show a small inverse solvent isotope effect $k\left(\mathrm{H}_{2} \mathrm{O}\right) / k\left(\mathrm{D}_{2} \mathrm{O}\right)=1.1$ and a positive entropy of activation $\left(\Delta S^{\ddagger}=3.07 \mathrm{cal} \mathrm{mol}^{-1} \mathrm{~K}^{-1}\right)$, which is consistent with water attack through a dissociative mechanism. In the basic region, solvolysis in ${ }^{18} \mathrm{O}-$ labelled water and $\mathrm{H}_{2} \mathrm{O} / \mathrm{MeOH}$ mixtures allowed detection of bimolecular hydrolysis and neighboring group participation, and to a minor degree, nucleophilic aromatic substitution. Under mildly basic conditions, a bimolecular dissociative mechanism is implicated through a solvent isotope effect of $k\left(\mathrm{HO}^{-}\right) / k\left(\mathrm{DO}^{-}\right)=0.5$ and a strongly negative entropy of activation $\left(\Delta S^{\ddagger}=-13.6 \mathrm{cal} \mathrm{mol}^{-1} \mathrm{~K}^{-}\right.$

$\left.{ }^{1}\right)$. Finally, at high $\mathrm{pH}$, an inverse solvent isotope effect of $k\left(\mathrm{HO}^{-}\right) / k\left(\mathrm{DO}^{-}\right)=0.6$ and a weakly negative entropy of activation $\left(\Delta S^{\ddagger}=-5.5 \mathrm{cal} \mathrm{mol}^{-1} \mathrm{~K}^{-1}\right)$ indicates that the formation of 1,2anhydrosugar is the rate determining step. 


\section{Introduction}

Carbohydrates are the most abundant polymer of biological origin on earth. Accordingly, the mechanism of their hydrolysis is of enduring interest. As a result of the powerful charge stabilization effects of the endocyclic oxygen on positive charge development at the anomeric carbon, an oxocarbenium ion intermediate or oxocarbenium-ion-like transition state feature extensively in almost all transformations at the anomeric centre. ${ }^{1}$ The lifetime of the glucopyranosyl cation in water is short and is estimated at 1-3 $\mathrm{ps}^{2,3}$ As a consequence, nucleophilic substitution reactions of hydroxylated glycosides tend to straddle the border of $\mathrm{S}_{\mathrm{N}} 1$ and $\mathrm{S}_{\mathrm{N}} 2$ reactions. The hydrolysis (or solvolysis) of glycosides of simple (alkyl) alcohols has been extensively studied, ${ }^{4}$ as well as that of other simple leaving groups such as azide (glycosyl azides), ${ }^{2}$ fluoride (glycosyl fluorides) ${ }^{5-7}$ or neutral amines (glycosyl pyridinium ions)..$^{3,5,8}$

The non-enzymatic hydrolysis reactions of aryl glycosides are less well studied, which is surprising as these compounds are widely used substrates for the study of glycosidases, Nature's catalysts for glycoside hydrolysis. Under acid-catalyzed conditions, ${ }^{9}$ hydrolysis involves heterolysis of the glycosidic bond, ${ }^{10}$ and aryl glycosides are hydrolysed more rapidly than alkyl glycosides, ${ }^{10,11}$ which is consistent with their better leaving group ability. Under identical acidic conditions, phenyl $\alpha$-D-glucoside is hydrolyzed approximately 50 -fold faster than methyl $\alpha$-D-glucopyranoside; the rate ratio is about 8 -fold for the $\beta$-series. ${ }^{10}$ Hammett reaction constants of $\rho=-0.006$ and -0.66 have been reported for acidic hydrolysis of aryl $\alpha$ and $\beta$-D-glucopyranosides, respectively. ${ }^{12,13}$

Under neutral conditions, methyl $\beta$-glucopyranoside hydrolyses with a rate constant of $4.7 \times 10^{-15} \mathrm{~s}^{-1}$ at $25^{\circ} \mathrm{C},{ }^{14}$ while 2,4-dinitrophenyl $\beta$-glucoside (DNPGlc) hydrolyses with a rate constant of $5.58 \times 10^{-6} \mathrm{~s}^{-1}$ at $37{ }^{\circ} \mathrm{C},{ }^{15}$ showing that a highly activated 2,4-dinitrophenoxide group confers significantly greater reactivity. The entropy of activation $\left(\Delta S^{\ddagger}\right)$ for these two processes are $-24 \mathrm{cal} \mathrm{mol}^{-1} \mathrm{~K}^{-1}$ (at $25^{\circ} \mathrm{C}$ ) and $33.8 \mathrm{cal} \mathrm{mol}^{-1} \mathrm{~K}^{-1}$ (at $37{ }^{\circ} \mathrm{C}$ ), respectively, suggesting that the uncatalyzed hydrolysis of methyl $\beta$-glucopyranoside involves a bimolecular process with significant participation by the nucleophile, ${ }^{14}$ while that of DNPGlc involves a more dissociative (ionic) process, possibly involving a short-lived oxocarbenium ion intermediate. ${ }^{15}$ Jencks reported a solvent kinetic isotope effect for the hydrolysis of $\alpha$ glucopyranosyl fluoride in the $\mathrm{pH}$ independent region of $k_{\mathrm{H}} / k_{\mathrm{D}}=0.9 .^{7}$ As this value is close to unity it shows limited fractionation and, like the hydrolysis of DNPGlc, is consistent with a 
dissociative mechanism for this substrate bearing a good fluoride leaving group.

Under basic conditions hydrolysis of aryl glycosides also involves cleavage of the glycosidic bond. ${ }^{16}$ Interestingly, 4-nitrophenyl $\beta$-glucoside (PNPGlc) is hydrolyzed 195-fold faster in $0.1 \mathrm{~N} \mathrm{NaOH}$ than in $0.1 \mathrm{~N} \mathrm{HCl}$ (both at $65^{\circ} \mathrm{C}$ ). ${ }^{17}$ Alkaline solvolysis reactions exhibit sharp sensitivity to substituent effects with Hammett reaction constants of $\rho=+2.8-4.0$ and +2.48 for aryl $\alpha$ - and $\beta$-D-glucopyranosides, respectively. ${ }^{12,13}$ These effects mean that while 4-nitrophenyl $\alpha$-D-glucopyranoside hydrolyses at approximately the same rate as the unsubstituted phenyl analogue under acidic conditions, under strongly basic conditions (3.9 N $\mathrm{NaOH})$ it hydrolyses approximately 300,000-fold faster than the phenyl analogue. ${ }^{13}$ Under basic conditions, phenyl $\beta$-D-glucopyranoside hydrolyses several orders of magnitude faster than phenyl $\alpha$-D-glucopyranoside, ${ }^{12,13}$ and there is compelling evidence for neighboring group participation in the basic solvolysis of aryl $\beta$-D-glucopyranosides involving a C2-oxyanion and proceeding through a 1,2-anhydro sugar. ${ }^{16}$ This includes substitution with retention of anomeric configuration when using methoxide, ${ }^{18}$ and the rate retardation induced by blocking the $\mathrm{C} 2$ oxygen with a methyl group. ${ }^{19}, 20$ For the related reaction of 4-nitrophenyl $\alpha$-Dmannopyranoside (which shares a 1,2-trans relationship), ${ }^{20}$ the carbon-13 kinetic isotope effect (KIE) for $\mathrm{C} 1$ is $(1.026 \pm 0.006),{ }^{21}$ which is in agreement with $\mathrm{S}_{\mathrm{N}} 2$ reactions on glycosides, ${ }^{22}$ and the ratio of $k_{\mathrm{L}} / k_{\mathrm{H}}>1$ indicates a concerted rather than dissociative mechanism. The oxygen$18 \mathrm{KIE}$ for the C2-oxygen is greater than unity $(1.044 \pm 0.0060)$, implicating its direct involvement in the reaction. ${ }^{21}$

Here we report the $\mathrm{pH}$-rate constant profile of the hydrolysis of PNPGlc. We distinguish four main mechanistic regimes (Figure 1). By exploration of buffer and solvent isotope effects, we show that PNPGlc undergoes specific acid catalyzed hydrolysis at low $\mathrm{pH}$, and uncatalyzed hydrolysis in the $\mathrm{pH}$ independent region when buffer concentration was extrapolated to zero. At high $\mathrm{pH}$ at two main mechanisms are observed: a bimolecular nucleophilic substitution under mildly basic conditions, and neighbouring group participation by the C2-oxyanion via a 1,2-anhydro sugar intermediate under strongly basic conditions. 

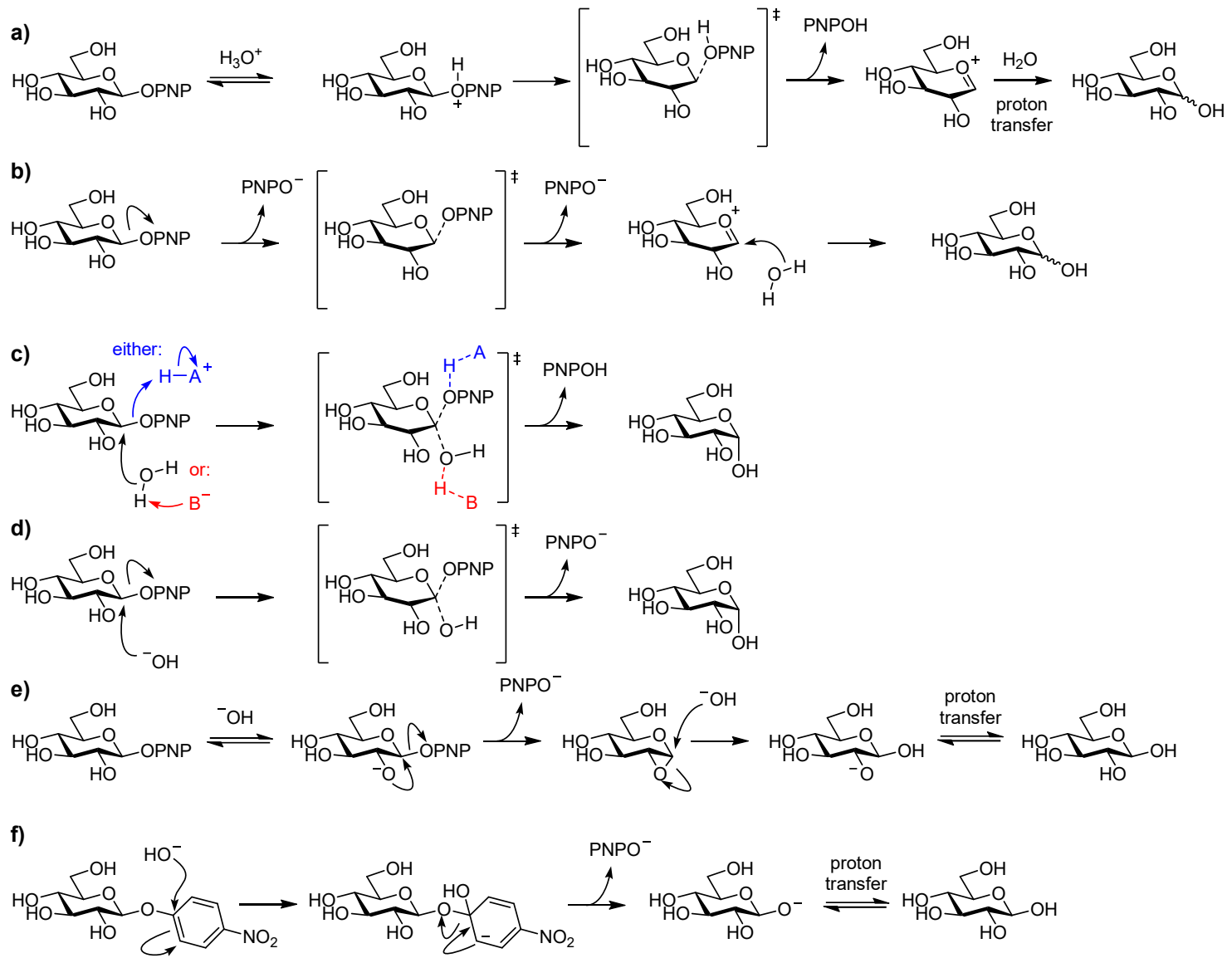

Figure 1. Mechanisms of hydrolysis of PNPGlc: (a) specific acid catalyzed (unimolecular);

(b) uncatalyzed dissociative; (c) general acid/base catalyzed; (d) biomolecular base-

promoted; (e) neighboring group participation by C2-oxyanion; (f) nucleophilic aromatic substitution.

\section{Results}

\section{1. pH rate profile for formation of 4-nitrophenol/phenolate from PNPGlc}

Reactions were conducted at elevated temperature, typically $90{ }^{\circ} \mathrm{C}$, by monitoring formation of the 4-nitrophenol/phenolate anion either in real time in a cuvette using a spectrophotometer or for slower reactions in sealed Wheaton vials after quenching with base. At the extremes of $\mathrm{pH}$ reaction rates were too fast at $90{ }^{\circ} \mathrm{C}$ to be accurately determined. In these cases, reactions were conducted at lower temperature and Arrhenius plots were used to extrapolate rates to $90{ }^{\circ} \mathrm{C}$. $\mathrm{pH}$ values of solutions and buffers at elevated temperature were calculated from $\mathrm{pH}$ measured at $25^{\circ} \mathrm{C}$ using the temperature sensitivity coefficients of the $\mathrm{p} K_{\mathrm{a}}$ values of $\mathrm{H}_{2} \mathrm{O}$ or of buffers. Reactions were performed in $2 \mathrm{M} \mathrm{NaCl}$ solution and corrected for salt effects by varying salt concentration from $0.25-2 \mathrm{M}$ and extrapolating to zero salt 
concentration.

The experimentally determined $\mathrm{pH}-$ rate profile, $\log \mathrm{k}$ versus $\mathrm{pH}$, for hydrolysis of PNPGlc at $90{ }^{\circ} \mathrm{C}$ is shown in Figure 2a, and is corrected for buffer and salt effects, and for the strongly basic region, a minor incursion of nucleophilic aromatic substitution. The plot reveals four distinct regions: the acidic region ( $\mathrm{pH}-1$ to 0 ), a $\mathrm{pH}$-independent region ( $\mathrm{pH} 1$ to 7), and two basic regions ( $\mathrm{pH} 8$ to 10 and 10 to 12 ). The overall rate law is given by equation 1 :

$$
k_{\mathrm{obs}}=k_{\mathrm{H}}\left[\mathrm{H}^{+}\right]+k_{\mathrm{uncat}}+k_{\mathrm{OH} 1}\left[\mathrm{HO}^{-}\right]+k_{\mathrm{NGP}}
$$

where $k_{\mathrm{H}}$ is the rate constant for the specific acid catalyzed reaction, $k_{\text {uncat }}$ is the rate constant for the uncatalyzed reaction, $k_{\mathrm{OH} 1}$ is the rate constant for the bimolecular reaction involving hydroxide, and $k_{\mathrm{NGP}}$ is the rate constant for neighboring group participation by $\mathrm{C} 2-$ oxyanion.

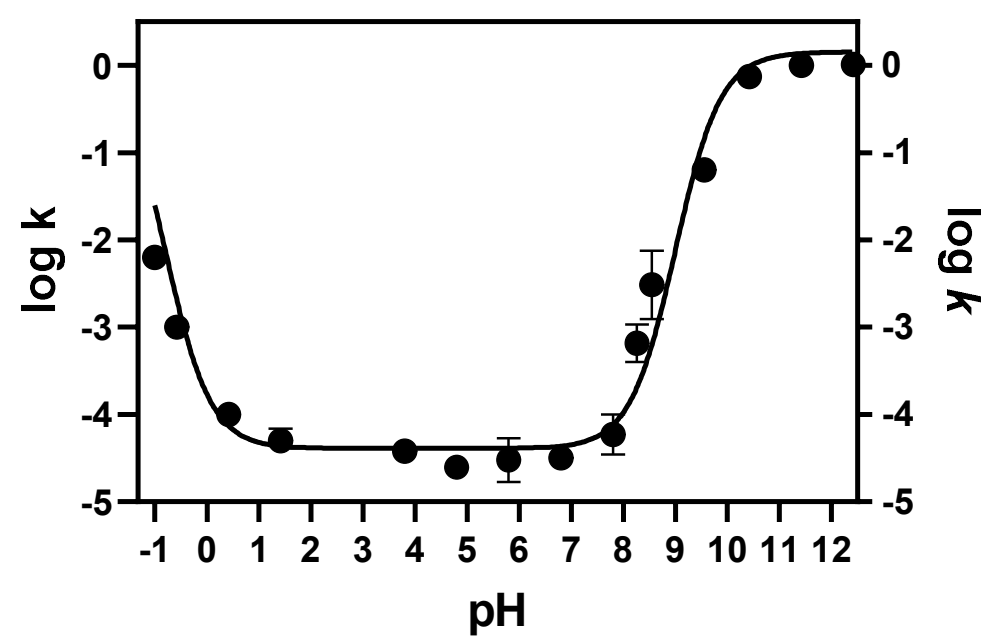

Figure 2. $\mathrm{pH}$ rate-constant profile for hydrolysis of PNPGlc corrected for $\mathrm{pH}$ at $90{ }^{\circ} \mathrm{C}$.

\section{Mechanism of hydrolysis in the acidic region}

Overend and co-workers noted that for the hydrolysis of PNPGlc in $2 \mathrm{~N}$ hydrochloric acid at $72{ }^{\circ} \mathrm{C}, 5-10 \%$ of a disaccharide product is formed, and inclusion of D-glucose in the reaction mixtures did not affect measured rates, indicating that disaccharide formation resulted from condensation of glucose released in the reaction. ${ }^{11}$ Here, ${ }^{1} \mathrm{H}$ NMR analysis of the reaction mixture obtained from the reaction of PNPGlc $(50 \mathrm{mM})$ at $\mathrm{pH}-0.8$ (corrected from $\mathrm{pH} 0.5$ measured at room temperature) at 50\% completion revealed exclusive formation of only 
$\mathrm{PNPOH}$ and glucose, and thus rates measured from quantifying production of $\mathrm{PNPOH} / \mathrm{PNPO}^{-}$ reflect exclusively hydrolysis.

Arrhenius activation parameters were calculated for the hydrolysis reaction in the acidic region. The rate of the hydrolysis of $1 \mathrm{mM}$ PNPGlc and $150 \mathrm{mM} \mathrm{NaCl}$ was measured at four different temperatures in $0.3 \mathrm{M} \mathrm{HCl}$ (Table S1, Figure S2). Plotting $\log k_{\mathrm{obs}}$ as a function of the inverse of temperature yielded the activation energy, $E_{a}$, and the pre-exponential factor, ln A, and allowed calculation of thermodynamic factors, the entropy of activation, $\Delta S^{\star}$, and the enthalpy of activation, $\Delta H^{*}$ (Table $\left.\mathbf{1}\right)$.

Table 1. Arrhenius parameters for hydrolysis of PNPGlc.

\begin{tabular}{ccccc}
\hline $\mathbf{p H}$ & $\begin{array}{c}\boldsymbol{E}_{\boldsymbol{a}} \\
\left(\mathbf{k c a l ~ m o l}^{-\mathbf{1}}\right)\end{array}$ & $\mathbf{I n} \mathbf{A}$ & $\begin{array}{c}\Delta \boldsymbol{S}^{\dagger a} \\
\left(\mathbf{c a l ~ m o l}^{\mathbf{- 1}} \mathbf{K}^{-\mathbf{1}}\right)\end{array}$ & $\begin{array}{c}\Delta \boldsymbol{H}^{\dagger} \\
\left(\mathbf{k c a l ~ m o l}^{-\mathbf{1}}\right)\end{array}$ \\
\hline 0.58 & 25.2 & 29.8 & 0.73 & 24.6 \\
6 & 29.0 & 31.0 & 3.07 & 28.4 \\
9.5 & 21.3 & 22.6 & -13.6 & 20.7 \\
14 & 18.9 & 26.7 & -5.5 & 18.3 \\
\hline
\end{tabular}

${ }^{a}$ at $298.1 \mathrm{~K}$

To investigate whether there is a salt effect, a series of reactions were conducted at $\mathrm{pH}$ 0 and varying the concentration of $\mathrm{NaCl}$ from $0.25-2 \mathrm{M}$ (Table S2). The plot of the measured rates gave a straight line (Figure S1), indicating a primary kinetic salt effect of $k_{\text {salt }}=0.403$ $\min ^{-1} \mathrm{M}^{-1}$, and allowing extrapolation to [salt] $=0$ where $k=0.00015 \mathrm{~min}^{-1}$.

The solvent isotope effect at $\mathrm{pH}-0.75$ was measured in solutions containing $\left[\mathrm{H}_{3} \mathrm{O}^{+}\right]=$ $1 \mathrm{M}$ or $\left[\mathrm{D}_{3} \mathrm{O}^{+}\right]=1 \mathrm{M}$ and $[\mathrm{NaCl}]=150 \mathrm{mM},[\mathrm{S}]=1 \mathrm{mM}$ at $75^{\circ} \mathrm{C}$. The measured rates were $k\left(\mathrm{D}_{3} \mathrm{O}^{+}\right)=(3.2 \pm 0.01) \times 10^{-3} \mathrm{~min}^{-1}$ and $k\left(\mathrm{H}_{3} \mathrm{O}^{+}\right)=(2.02 \pm 0.04) \times 10^{-3} \mathrm{~min}^{-1}$, giving a solvent isotope effect of $k\left(\mathrm{H}_{3} \mathrm{O}^{+}\right) / k\left(\mathrm{D}_{3} \mathrm{O}^{+}\right)=0.63 \pm 0.02$ (Table S3). Using the method of fractionation factors, ${ }^{23}$ the calculated solvent isotope effect for the specific acid catalyzed process, $\varphi^{\mathrm{R}} / \varphi^{\mathrm{P}}=$ 0.476 (Table S4).

\section{Mechanism of hydrolysis in the $p H$-independent region}

Rates measured for reactions in the $\mathrm{pH}$ independent region $\mathrm{pH}$ 3.8-6.8, using phosphate/citrate or phosphate buffer in $2 \mathrm{M} \mathrm{NaCl}$ ) of the $\mathrm{pH}$-rate profile give a line of best fit with a slope of $k_{\mathrm{obs}}=3.0 \times 10^{-5} \mathrm{~min}^{-1}$ (Figure 2a). Reaction rates in this region therefore have close to zero dependency on $\left[\mathrm{H}^{+}\right]$, and in this range may occur through uncatalysed hydrolysis 
( $\left.k_{\text {uncat }}\right)$, or mechanisms involving general acid/base catalysis, nucleophilic participation by buffer $\left(k_{\text {buffer }}\right)$ or salt effects ( $\left.k_{\text {salt }}\right)$. The empirical rate law that fits this analysis is equation 2 :

$$
k_{\text {obs }}=k_{\text {uncat }}+k_{\text {buffer }}[\text { buffer }]+k_{\text {salt }}[\text { salt }] \quad \text { eq. } 2
$$

Initially, we analysed the products of the reaction to ensure that measured rates are for hydrolysis. ${ }^{1} \mathrm{H}$ NMR spectroscopy revealed only the formation of glucose and 4-nitrophenol. To assess whether $\mathrm{NaCl}$ participates in the reaction, we first examined the effect of changing $[\mathrm{NaCl}]$. The plot of $[\mathrm{NaCl}]$ versus rate was almost flat, with $k_{\text {salt }}=(5.2 \pm 1.1) \times 10^{-6} \mathrm{M}^{-1} \mathrm{~min}^{-1}$, indicating essentially no salt effect (Figure S3, Table S5). Next, we independently varied the cation (to $\mathrm{KCl}$ ) and anion (to $\mathrm{NaClO}_{4}$ ) and examined the effects upon reaction rates. At $2 \mathrm{M}$ salt, the rate decreased (1.5 \pm 0.2$)$-fold in $\mathrm{KCl}$ versus $\mathrm{NaCl}$, and by $(2.0 \pm 0.2)$-fold in $\mathrm{NaClO}_{4}$, indicating limited salt participation, even at high concentrations and thus $k_{\text {salt }}=0$ (Figure S3, Table S5). Variation of [buffer] under conditions of pseudo constant ionic strength, in this case with $[\mathrm{NaCl}]=2 \mathrm{M}$ at $\mathrm{pH} 4$, gave a plot with slope $k_{\text {buffer }}=5.11 \times 10^{-5} \mathrm{M}^{-1} \min ^{-1}$ (Table S6, Figure S4).

Collectively, the above experiments define $k_{\text {buffer }}$ and $k_{\text {salt }}$ and allow calculation of the rate constant for the uncatalyzed hydrolysis reaction $\left(k_{\text {uncat }}\right)$, the thermodynamic parameters (measured at pH 5.8, Table S7, Figure S5, Table 1), and the solvent isotope effect. The solvent isotope effect for the uncatalyzed reaction was measured in $\mathrm{H}_{2} \mathrm{O}$ or $\mathrm{D}_{2} \mathrm{O}$ solvent, $\mathrm{pH}=\mathrm{pD} 6.8$, with $[\mathrm{NaCl}]=150 \mathrm{mM}$ and $[$ buffer $]=0.005 \mathrm{M}$. The measured rates were: $k_{\text {uncat }}\left(\mathrm{D}_{2} \mathrm{O}\right)=$ $(3.02 \pm 0.17) \times 10^{-5} \mathrm{~min}^{-1}$ and $k_{\text {uncat }}\left(\mathrm{H}_{2} \mathrm{O}\right)=(3.40 \pm 0.25) \times 10^{-5} \mathrm{~min}^{-1}$ (Figure 3a, Table S3), for a solvent isotope effect of $k_{\text {uncat }}\left(\mathrm{H}_{2} \mathrm{O}\right) / k_{\text {uncat }}\left(\mathrm{D}_{2} \mathrm{O}\right)=1.1 \pm 0.1$.

a)

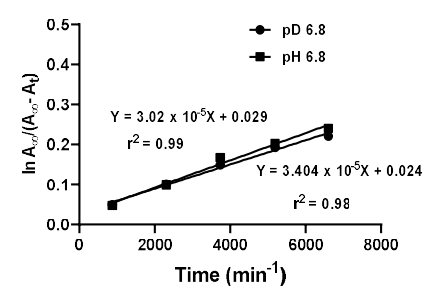

b)

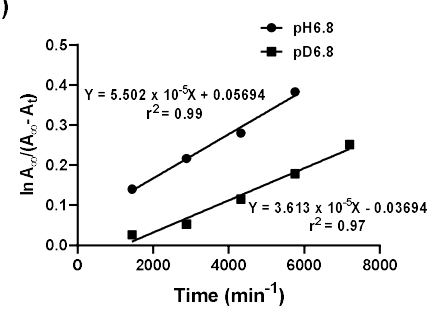

c)

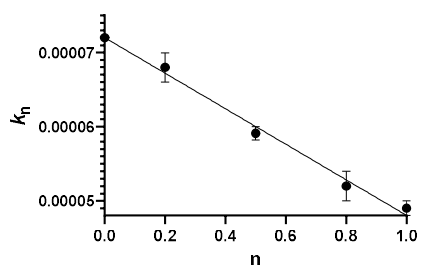

Figure 3. Reactions in the $\mathrm{pH}$ independent region $(\mathrm{pH}=6.8)$ at $90{ }^{\circ} \mathrm{C}$. (a) Solvent isotope effect at [buffer] $=0.005$ M. (b) Solvent isotope effect for [buffer] $=1$ M. (c) Proton inventory at $[$ buffer $]=1 \mathrm{M}, \mathrm{pH} 5.8$.

In order to probe the nature of the buffer effect, we initially tested for general acid/base catalysis by measuring a solvent isotope effect for [buffer] $=1 \mathrm{M}$, conducted in $\mathrm{H}_{2} \mathrm{O}$ and $\mathrm{D}_{2} \mathrm{O}$ 
at $\mathrm{pH}$ 3.8. Solvent isotope effects allow detection of general acid/base catalysis by measuring the number of protons in flight in the rate determining step. The solvent isotope effect, $k_{\mathrm{H}} / k_{\mathrm{D}}=$ $1.5 \pm 0.1$, which indicates general acid/base catalysis (Table S3, Figure 3b). While this solvent isotope effect gives evidence for general acid/base catalysis, it does not rule out nucleophilic participation by buffer. To establish whether phosphate or citrate in the buffer participates in the reaction, we repeated the $\mathrm{pH} 3.8$ rate measurements in $1 \mathrm{M}$ acetate buffer (with $2 \mathrm{M} \mathrm{NaCl}$ ) at the same $\mathrm{pH}$ and observed no significant difference in rates. However, this data does not allow clear conclusions to be drawn as the $\mathrm{p} K_{\mathrm{a}}$ values for acetic acid $\left(\mathrm{p} K_{\mathrm{a}} 4.75\right)$ and citric acid $\left(\mathrm{p} K_{\mathrm{a} 2} 4.75\right)$ are similar, and they may engage in nucleophilic participation to similar degrees. Attempts to detect the formation of a glycosyl acetate by NMR analysis of the product mixture were unsuccessful, but the failure to observe this species is inconclusive as to whether nucleophilic participation occurs.

We next sought to determine the number of protons in flight in the transition state of the reaction in buffer in which general catalysis is implicated. The proton inventory technique is a solvent isotope-effect experiment that gives information about the number of protons transferred in a chemical reaction. ${ }^{24}$ Measurements are made of the solvent isotope effect in varying mixtures of light and heavy solvent. If the proton inventory plot is linear, only one proton is involved in the reaction, and if the proton inventory is curved, at least two protons are involved.

The solvent isotope effect in $1 \mathrm{M}$ phosphate buffer at $90{ }^{\circ} \mathrm{C}$ was $k_{\mathrm{H}} / k_{\mathrm{D}}=1.4 \pm 0.09$. The inverse solvent isotope effect indicates that the protonation step is involved in the rate determining step and the reaction at high buffer concentration proceeds with general acid/base catalysis. Next, we measured the rate in a 20,50 and 80\% mixtures of light and heavy water in $1 \mathrm{M}$ buffer and $2 \mathrm{M} \mathrm{NaCl}$ at $90{ }^{\circ} \mathrm{C}$ (Table S8). The measured rate constants for different mixtures of isotopic solvents were plotted against the fraction of deuterium $(n)$ and yielded a linear plot (Figure 3c). Because plots of low curvature can be difficult to distinguish from linear plots, this data should be examined at the point of greatest curvature, namely $k_{0.5}$. The observed rate at $k_{0.5}=(5.91 \pm 0.09) \times 10^{-5}$ is in good agreement with the mean $\left(k_{0}\right.$ and $\left.k_{1}\right)=$ $(5.98 \pm 0.08) \times 10^{-5}$. Thus, these data suggest that the solvent isotope effect arises from a single hydrogenic site in the transition state; that is, only one proton is undergoing transfer in the rate- 
determining step. As the 4-nitrophenolate leaving group can stabilize negative charge, we suggest that the proton in flight is involved in base deprotonation of the water nucleophile.

\section{Mechanism of hydrolysis in the basic region}

(i) Mechanism under mildly basic conditions ( $\mathrm{pH} 7.8-8.55)$

${ }^{1} \mathrm{H}$ NMR analysis of $\mathrm{pH} 7.8,8.26$ and 8.55 reaction mixtures at $50 \%$ completion revealed only substrate, $\mathrm{PNPOH} / \mathrm{PNPO}^{-}$, and glucose. In order to determine whether product formation occurred through nucleophilic substitution at $\mathrm{Cl}$ or by nucleophilic aromatic substitution, reactions were conducted in $\mathrm{H}_{2}{ }^{18} \mathrm{O}$ and then analysed by mass spectrometry in negative ion mode. This revealed the presence of $\mathrm{PNPO}^{-}$as $m / z 138.02$, corresponding to the ${ }^{16} \mathrm{O}$ isotopomer, with no detectable ${ }^{18} \mathrm{O}$-labelled product. Thus, rates measured from quantifying production of $\mathrm{PNPO}^{-}$reflect only the bimolecular hydrolysis reaction.

To test for buffer participation, we varied buffer concentration under conditions of pseudo constant ionic strength, with $[\mathrm{NaCl}]=2 \mathrm{M}$ at $90{ }^{\circ} \mathrm{C}$. This gave plots with slope of essentially zero $\left(\mathrm{pH} 7.8,(1.0 \pm 0.5) \times 10^{-4} \mathrm{M}^{-1} \mathrm{~min}^{-1}\right.$; $\mathrm{pH} 8.26,(-4.5 \pm 5.0) \times 10^{-4} \mathrm{M}^{-1} \mathrm{~min}^{-1}$;

$\left.\mathrm{pH} 8.55,(-3.1 \pm 4.2) \times 10^{-3} \mathrm{M}^{-1} \mathrm{~min}^{-1}\right)$, indicating that the rate of reaction is independent of buffer concentration across this $\mathrm{pH}$ range. There was no significant salt effect. The slope of the plot of $k$ versus $\mathrm{pH}$ for $\mathrm{pH} 8.26-9.55$ was $1.5 \pm 0.2$, which is consistent with the biomolecular base-promoted mechanism in Figure 1d.

The above analysis allowed calculation of the thermodynamic parameters for the biomolecular base-promoted hydrolysis reaction (Table S9, Figure S6, Table 1), and the solvent isotope effect. The solvent isotope effect for the biomolecular base-promoted hydrolysis reaction was measured at $\mathrm{pD}=\mathrm{pH}=9.1$ and $90^{\circ} \mathrm{C}$. The measured rates were: $k\left(\mathrm{DO}^{-}\right.$ )$=(1.77 \pm 0.16) \times 10^{-3} \mathrm{~min}^{-1}$ and $k\left(\mathrm{HO}^{-}\right)=(9.01 \pm 0.29) \times 10^{-4} \mathrm{~min}^{-1}$, for a solvent isotope effect of $k\left(\mathrm{HO}^{-}\right) / k\left(\mathrm{DO}^{-}\right)=0.5 \pm 0.1$ (Table S3). The solvent isotope effect for the biomolecular process calculated using solvent isotope fractionation factors is 0.476 (Table S4).

(ii) Mechanism under strongly basic conditions

At $\mathrm{pH} 12.42$ and $90{ }^{\circ} \mathrm{C},{ }^{1} \mathrm{H}$ NMR analysis of the product mixture of reactions run to $50 \%$ completion revealed $\mathrm{PNPO}^{-}$, and a complex set of peaks assigned as the basedecomposition product of glucose and a new product with a characteristic $\mathrm{H} 1$ signal at $\delta 5.30$ ppm in $\mathrm{D}_{2} \mathrm{O}$ that was assigned as 1,6-anhydroglucose. The observation of 1,6-anhydroglucose provides evidence for neighboring group participation involving substitution of the anomeric 
group by the substrate 2-oxyanion, via a 1,2-anhydro sugar (epoxide) intermediate. However, the 1,2-anhydrosugar intermediate can partition in two ways: either by nucleophilic substitution involving intramolecular reaction with the 6-hydroxyl group (leading to the 1,6-anhydro sugar, which is stable to base), or by reaction with hydroxide (leading to glucose, which decomposes under the basic conditions of the reaction).

In order to determine whether product formation occurred through nucleophilic substitution at $\mathrm{C} 1$ or by nucleophilic aromatic substitution, reactions were conducted in $\mathrm{H}_{2}{ }^{18} \mathrm{O}$ and then analysed by mass spectrometry in negative ion mode. This revealed the presence of $\mathrm{PNPO}^{-}$as $\mathrm{m} / \mathrm{z} 138.02$, corresponding to the ${ }^{16} \mathrm{O}$ isotopomer, and a second peak at $\mathrm{m} / \mathrm{z} 140.02$, corresponding to the ${ }^{18} \mathrm{O}$ isotopomer, in a ratio of 99.1:0.89. This data demonstrate that nucleophilic aromatic substitution contributes just under $1 \%$ of the rate observed by quantifying production of $\mathrm{PNPO}^{-}$.

To investigate the partitioning of the 1,2-anhydrosugar intermediate between intramolecular substitution and hydroxide substitution, the reaction was repeated in 1:1 $\mathrm{MeOH} / \mathrm{H}_{2} \mathrm{O}$ with $0.5 \mathrm{M} \mathrm{NaOH}$ at $55^{\circ} \mathrm{C}\left(\mathrm{pH}\right.$ 12.96). ${ }^{1} \mathrm{H}$ NMR spectroscopy revealed the formation of a mixture of methyl $\alpha$-D-glucopyranoside, methyl $\beta$-D-glucopyranoside and levoglucosan in a ratio of 10:18:72. As explained earlier, levoglucosan arises through neighboring group participation by a C2-oxyanion, which also produces methyl $\beta$-Dglucopyranoside. On the other hand, methyl $\alpha$-D-glucopyranoside arises exclusively by bimolecular substitution. The $\mathrm{p} K_{\mathrm{a}}$ value of $\mathrm{MeOH}$ is 15.3 at $25^{\circ} \mathrm{C}$. Assuming the temperature dependence of the $\mathrm{p} K_{\mathrm{a}}$ of $\mathrm{MeOH}$ is similar to that of water ( $\left.\mathrm{p} K_{\mathrm{a}} 13.26\right)$, for $1: 1 \mathrm{MeOH} / \mathrm{H}_{2} \mathrm{O}$ with $0.5 \mathrm{M} \mathrm{NaOH}$ the $\left[\mathrm{MeO}^{-}\right]=0.02$. This allows correction of the observed rate of PNP formation at $\mathrm{pH} 12.96$.

To test for buffer participation, we varied [buffer] under conditions of pseudo constant ionic strength, with $[\mathrm{NaCl}]=2 \mathrm{M}$ at $55^{\circ} \mathrm{C}$. This gave a plot with slope of $1.73 \times 10^{-3} \pm 0.0023$ $\mathrm{M}^{-1} \mathrm{~min}^{-1}$, indicating a minor buffer effect. The salt effect in the weakly basic region was tested by measuring the reaction rates in $1 \mathrm{M} \mathrm{NaCl}\left(k=(0.90 \pm 0.03) \times 10^{-5} \mathrm{~min}^{-1}\right)$ and $0.25 \mathrm{M} \mathrm{NaCl}$ $\left(k=(1.0 \pm 0.04) \times 10^{-5} \mathrm{~min}^{-1}\right)$ at $\mathrm{pH} 8.26$ at $90^{\circ} \mathrm{C}$, and indicating that in the weakly basic region there is no significant salt effect.

The above allowed calculation of the thermodynamic parameters for the neighbouring group participation reaction ( $\mathrm{pH}$ 12.42, Table S11, Figure S8, Table 1), and the solvent isotope effect. The solvent isotope effect was measured in $\mathrm{H}_{2} \mathrm{O}$ or $\mathrm{D}_{2} \mathrm{O}$ solvent at $\mathrm{pH}=\mathrm{pD}$ 
13.1, with $[\mathrm{NaOD}]=[\mathrm{NaOH}]=1 \mathrm{M}$ and $[\mathrm{NaCl}]=150 \mathrm{mM}$ at $55^{\circ} \mathrm{C}$. The measured rates were: $k\left(\mathrm{DO}^{-}\right)=(1.0 \pm 0.11) \times 10^{-2} \mathrm{~min}^{-1}$ and $\left.k\left(\mathrm{HO}^{-}\right)=(6.0 \pm 0.9) \times 10^{-3} \mathrm{~min}^{-1}\right)$, allowing calculation of a solvent isotope effect of $k\left(\mathrm{HO}^{-}\right) / k\left(\mathrm{DO}^{-}\right)=0.6 \pm 0.18$ (Table S3). The calculated solvent isotope effect based on solvent isotope fractionation factors for the intermolecular reaction is 0.56 (Table S4).

\section{Discussion}

The $\mathrm{pH}$ rate profile for PNPGlc hydrolysis (Figure $\mathbf{2 b}$ ) was calculated from the $\mathrm{pH}$ rate profile for formation of $\mathrm{PNPOH} / \mathrm{PNPO}^{-}$(Figure 2a) by careful measurement of individual contributing reactions and correction for their contribution to the observed rates (Table S12). The profile gives evidence for at least 4 mechanistic regimes: at low $\mathrm{pH}$, in the intermediate $\mathrm{pH}$ range, in the mildly basic region, and at high $\mathrm{pH}$.

In the acidic region, the solvent kinetic isotope effect was $k\left(\mathrm{H}_{3} \mathrm{O}^{+}\right) / k\left(\mathrm{D}_{3} \mathrm{O}^{+}\right)=$ $0.63 \pm 0.02$. The inverse kinetic isotope effect indicates that there is a greater preference for deuteration $\left(\mathrm{D}^{+}\right)$than protonation of the substrate and that the specific acid catalysed hydrolysis of PNPGlc is a stepwise mechanism. Interpretation of solvent KIEs is complicated by the contributions from primary effects for protons undergoing transfer, and secondary effects, for example because of deuteration at exchangeable positions. Using the method of fractionation factors, and assuming a specific acid catalyzed mechanism, the calculated isotope fractionation factor $\varphi$ for the hydrolysis of PNPGlc at $\mathrm{pD}-0.41$ at $75{ }^{\circ} \mathrm{C}$ was 0.48 . The positive entropy of activation $\left(\Delta S^{\ddagger}=0.73 \mathrm{cal} \mathrm{mol}^{-1} \mathrm{~K}^{-1}\right)$ in the acidic region is consistent with a unimolecular transition state. Collectively this data is consistent with the reaction mechanism shown in Figure 1a, which involves a specific acid catalysed reaction in which the substrate is converted to its conjugate acid, followed by a rate-limiting reaction with $\mathrm{H}_{2} \mathrm{O}$. This data is consistent with observations made for methyl $\alpha$ - and $\beta$-glucopyranosides ${ }^{25}$ and -xylopyranosides. ${ }^{4}$

In the $\mathrm{pH}$ independent region there was small solvent isotope effect $k\left(\mathrm{H}_{2} \mathrm{O}\right) / k\left(\mathrm{D}_{2} \mathrm{O}\right)=$ $1.1 \pm 0.1$. This compares favourably with the solvent isotope effect of $k\left(\mathrm{H}_{2} \mathrm{O}\right) / k\left(\mathrm{D}_{2} \mathrm{O}\right)=0.93$ measured by Banait and Jencks for the hydrolysis of $\alpha$-glucopyranosyl fluoride at $30{ }^{\circ} \mathrm{C}$ in the $\mathrm{pH}$ independent region. ${ }^{7}$ A positive entropy of activation of $\Delta S^{\ddagger}=3.07 \mathrm{cal} \mathrm{mol}^{-1} \mathrm{~K}^{-1}$ was measured, similar to that for the acidic region, which is again consistent with a unimolecular transition state. for the hydrolysis of PNPGlc. Together these data indicate that the uncatalysed hydrolysis of PNPGlc proceeds through a dissociative mechanism to give short-lived glucosyl oxocarbenium ion, followed by nucleophilic attack of water molecule. The positive entropy of 
activation is inconsistent with a bimolecular process, and the observed solvent KIE is close to unity, which is consistent with a calculated isotope fraction factor of 1 for the dissociative mechanism in Figure 1b. The entropy of activation $\left(\Delta S^{\ddagger}=3.07 \mathrm{cal} \mathrm{mol}^{-1} \mathrm{~K}^{-1}\right)$ is positive, but smaller than that measured for the hydrolysis of DNPGlc $\left(\Delta S^{\ddagger}=33.8 \mathrm{cal} \mathrm{mol}^{-1} \mathrm{~K}^{-1}\right),{ }^{15}$ and distinct from the negative value measured for hydrolysis of methyl $\beta$-glucopyranoside $\left(\Delta S^{\ddagger}=\right.$ $\left.-24 \mathrm{cal} \mathrm{mol}^{-1} \mathrm{~K}^{-1}\right){ }^{14}$ Extrapolation of the rate for hydrolysis of PNPGlc to ambient temperature, $k_{25^{\circ} \mathrm{C}}=2.86 \times 10^{-10} \mathrm{~s}^{-1}$ reveals it is approximately five orders of magnitude faster than that for hydrolysis of methyl $\beta$-glucopyranoside $k_{25^{\circ} \mathrm{C}}=1.9 \times 10^{-15} \mathrm{~s}^{-1} \cdot{ }^{14}$

Under weakly basic conditions the reaction was first order in base, and had a solvent isotope effect of $0.5 \pm 0.1$, which compares favourably to the solvent isotope effect of 0.66 reported by Banait and Jencks for the hydroxide mediated hydrolysis of $\alpha$-glucopyranosyl fluoride at $30^{\circ} \mathrm{C} .{ }^{7}$ In this region the reaction had a strongly negative entropy of activation $\left(\Delta S^{\dagger}\right.$ $=-13.6 \mathrm{cal} \mathrm{mol}^{-1} \mathrm{~K}^{-1}$ ) which is consistent with an ordered bimolecular transition state. Jencks demonstrated that the reaction of anionic nucleophiles with $\alpha$-glucopyranosyl fluoride has a linear dependence on concentration of the nucleophile and occurs with inversion of configuration, providing evidence for a concerted bimolecular $\mathrm{S}_{\mathrm{N}} 2$ reaction. ${ }^{7}$ We interpret our results in a similar manner, and thus that at low concentrations, hydroxide reacts with PNPGlc in a concerted, bimolecular reaction as shown in Figure 1d.

Under strongly basic conditions product analysis of the hydrolysis reaction in ${ }^{18} \mathrm{O}$ water, and in a mixture of methanol/water, provide evidence for nucleophilic aromatic substitution (Figure 1f), bimolecular $\mathrm{S}_{\mathrm{N}} 2$ substitution at the anomeric position (Figure 1d), and a mechanism involving neighboring group participation that leads to both glucose and 1,6anhydroglucose (Figure 1e). The major route at $\mathrm{pH} 12.42$ at $90{ }^{\circ} \mathrm{C}$ is neighboring group participation. The reaction displayed an inverse solvent isotope effect of $k\left(\mathrm{HO}^{-}\right) / k\left(\mathrm{DO}^{-}\right)=0.6$ \pm 0.2 . These solvent isotope effects are similar to those reported by Gasman and Johnson for hydrolysis of 4-nitrophenyl $\beta$-D-galactoside $\left(\mathrm{PNPGal} ; k\left(\mathrm{HO}^{-}\right) / k\left(\mathrm{DO}^{-}\right)=0.73 \pm 0.02\right)$ and PNPMan $\left(k\left(\mathrm{HO}^{-}\right) / k\left(\mathrm{DO}^{-}\right)=0.70 \pm 0.01\right) .{ }^{20}$ This inverse solvent isotope effect indicates that 2oxyanion attack is the rate limiting step. The activation parameters for PNPGlc are $\Delta S^{\ddagger}=-5.5$ cal $\mathrm{mol}^{-1} \mathrm{~K}^{-1}$, and $\Delta H^{\star}=18.3 \mathrm{kcal} \mathrm{mol}^{-1}$; the corresponding values for PNPGal are $\Delta S^{\ddagger}=-7.3$ cal $\mathrm{mol}^{-1} \mathrm{~K}^{-1}$, and $\Delta H^{*}=21.9 \mathrm{kcal} \mathrm{mol}^{-1}{ }^{20}$ The weakly negative entropy of activation is consistent with a unimolecular process involving a cyclic transition state.

\section{Conclusion}


In this article we report the pH-rate profile for the hydrolysis of PNPGlc, which allowed the identification of four major mechanistic regimes, and detailed kinetic studies allowed identification of the mechanism that operate within these ranges. The present work highlights the complexity of hydrolytic reactions of 1,2-trans glycosides and provides useful reference data to understand the rate enhancements achieved by enzymes.

\section{Experimental}

\section{General}

4-Nitrophenyl $\beta$-D-glucopyranoside (PNPGlc) was synthesized as $\operatorname{described}^{26}$ and recrystallized to purity, as assessed by ${ }^{1} \mathrm{H}$ NMR spectroscopy. NMR spectroscopy was conducted using 400 and $600 \mathrm{MHz}$ instruments. ${ }^{18} \mathrm{O}$-water (Marshall Isotopes Ltd, 97\%) and ${ }^{2} \mathrm{H}$-water (Sigma Aldrich, 99.9\%) were used for mechanism and kinetic studies, respectively. Mass spectrometry was performed using electrospray ionization and a quadrupole time-offlight instrument. $\mathrm{pH}$ values of solutions and buffers at elevated temperature were calculated from $\mathrm{pH}$ measured at $25^{\circ} \mathrm{C}$ using the temperature sensitivity coefficients of the $\mathrm{p} K_{\mathrm{a}}$ values of $\mathrm{H}_{2} \mathrm{O}$ or of buffers, using by $\Delta \mathrm{pH}=\Delta \mathrm{p} K_{\mathrm{a}}$, and $\mathrm{d}\left(\mathrm{p} K_{\mathrm{a}}\right) / \mathrm{dT}$ describes the change of the $\mathrm{p} K_{\mathrm{a}}$ at an increase of temperature by $1{ }^{\circ} \mathrm{C} .{ }^{27}$ Water: $\mathrm{p} K_{\mathrm{w}}=12.42 ;{ }^{28}$ phosphate/citric acid, $\mathrm{pH}$ range $4-5$ $\mathrm{p} K_{\mathrm{a}}=7.20,2.79$, respectively, temperature coefficient $\left.=-0.0028 / 0\right)$; phosphate, $\mathrm{pH}$ range 6-8, $\mathrm{p} K_{2}=7.20$, temperature coefficient $=-0.0028$, and bicarbonate/carbonate, $\mathrm{pH}$ range 9.2-11, $\mathrm{p} K_{\mathrm{a} 1}=6.35$, temperature coefficient $=-0.0055, \mathrm{p} K_{\mathrm{a} 2}=10.32$, temperature coefficient $=-0.009$.

Measurement of reaction rates. A Cary $3500 \mathrm{UV}$-Vis spectrophotometry was used to monitor rates of cleavage of PNPGlc by monitoring the released 4-nitrophenol/4-nitrophenolate anion. For continuous assays, reactions were monitored at the isosbestic point of $350 \mathrm{~nm}$ using an extinction coefficient $(\varepsilon), \varepsilon_{\mathrm{PNP}}=6.212 \mathrm{mM}^{-1} \mathrm{~cm}^{-1}$. For stopped assays, an aliquot was taken from the reaction mixture and alkalinized to $\mathrm{pH} 10$ by quenching with $2 \mathrm{M} \mathrm{Na}_{2} \mathrm{CO}_{3}$, then 4nitrophenolate anion was quantified at $400 \mathrm{~nm}$ using $\varepsilon_{\mathrm{PNP}}=16.14 \mathrm{mM}^{-1} \mathrm{~cm}^{-1}$. All spectrophotometric measurements were carried out under pseudo-first order conditions with low substrate concentration (1-5 mM) and high concentration of the relevant catalyst $\left(\mathrm{H}_{3} \mathrm{O}^{+}\right.$, buffer, or $\mathrm{HO}^{-}$). Spectroscopic absorbances were measured against a reference cell containing $1 \mathrm{M} \mathrm{HCl}$ or $\mathrm{NaOH}$, or $2 \mathrm{M} \mathrm{Na}_{2} \mathrm{CO}_{3}$.

Reaction rates at varying $\mathbf{p H}$. Individual reactions contained 1-5 mM PNPGlc. For reactions at $\mathrm{pH}<4$, solutions were prepared by dilution of aq $\mathrm{HCl}$ and contained $2 \mathrm{M} \mathrm{NaCl}$. In the range 
pH 4-11 phosphate and carbonate buffers were used, typically $1 \mathrm{M}$ buffer and $2 \mathrm{M} \mathrm{NaCl}$. In the range of $\mathrm{pH} 12-14$ standardized $\mathrm{NaOH}$ was diluted to the final $\mathrm{pH}$ and contained $2 \mathrm{M} \mathrm{NaCl}$. Reactions were heated at $75-90{ }^{\circ} \mathrm{C}$ for $2-196 \mathrm{~h}$. Reactions at $\mathrm{pH} 0$ and $>11$ were performed in semi-micro quartz cuvettes at $<75^{\circ} \mathrm{C}$, and changes in absorbance monitored directly in a UVVis spectrophotometer at $350 \mathrm{~nm}$, with rates calculated using the Beer-Lambert law. Very slow reactions suffered from evaporation of solvent, and in these cases, reactions were performed in tightly-sealed Wheaton vials. At various time points aliquots were sampled and added to $2 \mathrm{M}$ $\mathrm{Na}_{2} \mathrm{CO}_{3}$ and the absorbance of the sample was measured directly at $400 \mathrm{~nm}$. Rates were determined using the Beer-Lambert law.

Salt effects. Reactions were performed by varying concentration of $\mathrm{NaCl}$ from $0.25-2 \mathrm{M}$. The data gave a straight line and extrapolation to $[\mathrm{NaCl}]=0$ allowed estimation of $k_{0}$ and slope of monomolecular rate constant. In the $\mathrm{pH}$-independent region reactions were conducted in water buffered by $0.005 \mathrm{M}$ phosphate buffer, with concentrations of $\mathrm{NaCl}$ varied in the range $0.25-2$ M. Sub-samples at different time intervals were studied by ${ }^{1} \mathrm{H}$ NMR spectroscopy.

Buffer effects. Rates were extrapolated to zero buffer by holding the $\mathrm{pH}$ constant and varying the buffer concentration. At $\mathrm{pH}$ values $<1.42$, a plot of rate versus [buffer] gave a straight line with $y$-intercept being the rate at zero buffer and the slope, $k_{\mathrm{G}}$, the general catalysed rate constant.

Product analysis. To assess the identity and relative proportions of products, reactions were run to approximately 50\% completion, then were evaporated to dryness. For NMR analysis, samples were dissolved in $d_{6}$-DMSO or $\mathrm{D}_{2} \mathrm{O}$. For mass spectrometric analysis samples were dissolved in $\mathrm{MeOH}$.

Activation parameters. The Arrhenius equation was used to calculate the thermodynamic parameters of the hydrolysis reaction in the acidic region. The rate of the hydrolysis of $1 \mathrm{mM}$ PNPGlc was measured at $350 \mathrm{~nm}$ in solutions at $\mathrm{pH}(-1$ to -0.17$)$ at $75-45^{\circ} \mathrm{C}$ and $150 \mathrm{mM}$ $\mathrm{NaCl}$ at four different temperatures. Plotting the natural logarithm of $k_{\mathrm{obs}}$ as a function of the inverse of the temperatures gives a straight line with slope of $\frac{-E_{a}}{R}$ and a $y$ intercept of $\ln \mathrm{A}$, and allowed calculation of the activation energy, $E_{a}$ and the pre-exponential factor in the Arrhenius relationship, ln A (eq. 3):

$$
\ln A=\ln k+E_{a} / R T_{1} \quad \text { eq. } 3
$$


The activation parameters allowed calculation of the enthalpy and entropy of activation at $298.1 \mathrm{~K}$, according to equations 4 and 5 derived from transition state theory:

$$
\begin{aligned}
& \Delta H^{\ddagger}=E_{\mathrm{a}}-\mathrm{RT} \\
& \Delta S^{\ddagger}=R\left(\ln A-\ln \frac{K_{B} T}{h}\right) R
\end{aligned}
$$

where $K_{\mathrm{B}}$ is Boltzmann constant, $h$ is Planck's constant, $\mathrm{T}$ is the temperature, and $\mathrm{R}$ is the ideal gas constant.

Solvent isotope effects. The solvent isotope effect in the acidic region was measured in solutions contained $\left[\mathrm{H}_{3} \mathrm{O}^{+}\right]=1 \mathrm{M}$ or $\left[\mathrm{D}_{3} \mathrm{O}^{+}\right]=1 \mathrm{M}$ (which was prepared by $1: 10$ dilution) and $[\mathrm{NaCl}]=150 \mathrm{mM}$, with $[\mathrm{PNPGlc}]=1 \mathrm{mM}$ at $75^{\circ} \mathrm{C}$. Rates were measured using a continuous assay at $350 \mathrm{~nm}$ in triplicate to either calculate standard deviation (SD) or standard error (SR).

The solvent isotope effect in the $\mathrm{pH}$ independent region was measured in $\mathrm{H}_{2} \mathrm{O}$ or $\mathrm{D}_{2} \mathrm{O}$ solvent $\mathrm{pH}=\mathrm{pD} 6.8$, with $[$ phosphate $]=150 \mathrm{mM},[\mathrm{NaCl}]=2 \mathrm{M}$, and $[\mathrm{PNPGlc}]=1 \mathrm{mM}$ at 90 ${ }^{\circ} \mathrm{C}$. Rates were measured in triplicate using a stopped assay after quenching with base.

The solvent isotope effect was measured in $\mathrm{H}_{2} \mathrm{O}$ or $\mathrm{D}_{2} \mathrm{O}$ solvent at $\mathrm{pH}=\mathrm{pD} 13.26$, with $[\mathrm{NaOD}]=[\mathrm{NaOH}]=1 \mathrm{M},[\mathrm{NaCl}]=150 \mathrm{mM}$, and $[\mathrm{PNPGlc}]=1 \mathrm{mM}$ at $75{ }^{\circ} \mathrm{C}$. Rates were measured in triplicate using a continuous assay.

For the proton inventory, rates were measured in solutions comprised of varying ratios of water and deuterium oxide. The data were analysed using the linear Gross-Butler equation (eq 6):

$$
\frac{\mathrm{k}_{\mathrm{n}}}{\mathrm{k}_{0}}=\frac{\left(1-\mathrm{n}+\mathrm{n} \varphi_{1}^{\mathrm{TS}}\right)}{\left(1-\mathrm{n}+\mathrm{n} \varphi_{1}^{\mathrm{GS}}\right)}
$$

where $k_{\mathrm{n}}=$ the rate constant at atom fractionation deuterium $\mathrm{n}, k_{0}=$ the rate constant in pure water, and $\varphi_{1}^{T S}$ and $\varphi_{1}^{G S}$ are the fractionation factors of the exchangeable proton in the transition and ground state.

Calculation of predicted solvent isotope effects. The solvent isotope effect was calculated using the isotopic fractionation factor $\varphi .{ }^{23}$ The isotopic fractionation factor is the preference of a hydrogen to be at any site in the solute over the solvent. Thus, in the equilibrium reaction where the substrate is converted to its conjugate acid the equilibrium fractionation factors 
defined by equation 7 allows the calculation of the preferred hydron site as an equilibrium ratio.

$$
\frac{K_{H}}{K_{D}}=\frac{[R D] /[R H]}{[R O H] /[R O D]} / \frac{[P D] /[P H]}{[P O D] /[P O H]}=\frac{\varphi_{R}}{\varphi_{P}} \quad \text { eq. } 7
$$

\section{Associated Content}

\section{Supporting information}

The Supporting Information is available free of charge at...

Additional data including kinetic measurements and calculations, Tables S1-13 and Figures S1-7 (PDF).

\section{Author Information}

\section{Corresponding Author}

Spencer J. Williams, Email: sjwill@unimelb.edu.au

\section{Notes}

The authors declare no competing financial interest.

\section{Acknowledgements}

This work was supported by a grant from the Australian Research Council (DP180101957). AA thanks Jazan University for financial support and thanks the Saudi Arabian Cultural Mission (SACM). 


\section{References}

1. Colombo, C.; Bennet, A. J., The physical organic chemistry of glycopyranosyl transfer reactions in solution and enzyme-catalyzed. Curr. Opin. Chem. Biol. 2019, 53, 145-157.

2. Amyes, T. L.; Jencks, W. P., Lifetimes of oxocarbenium ions in aqueous solution from common ion inhibition of the solvolysis of .alpha.-azido ethers by added azide ion. $J$. Am. Chem. Soc. 1989, 111, 7888-7900.

3. Zhu, J.; Bennet, A. J., Hydrolysis of (2-Deoxy- $\alpha$-d-Glucopyranosyl)pyridinium Salts: The 2-Deoxyglucosyl Oxocarbenium Is Not Solvent-Equilibrated in Water. J. Am. Chem. Soc. 1998, 120, 3887-3893.

4. Indurugalla, D.; Bennet, A. J., A Kinetic Isotope Effect Study on the Hydrolysis Reactions of Methyl Xylopyranosides and Methyl 5-Thioxylopyranosides: Oxygen versus Sulfur Stabilization of Carbenium Ions. J. Am. Chem. Soc. 2001, 123, 10889-10898.

5. Sinnott, M. L.; Jencks, W. P., Solvolysis of D-glucopyranosyl derivatives in mixtures of ethanol and 2,2,2-trifluoroethanol. J. Am. Chem. Soc. 1980, 102, 2026-2032.

6. Banait, N. S.; Jencks, W. P., Reactions of anionic nucleophiles with a-Dglucopyranosyl fluoride in aqueous solution through a concerted, $\mathrm{A}_{\mathrm{N}} \mathrm{D}_{\mathrm{N}}\left(\mathrm{S}_{\mathrm{N}} 2\right)$ mechanism. $J$. Am. Chem. Soc. 1991, 113, 7951-7958.

7. Banait, N. S.; Jencks, W. P., General-acid and general-base catalysis of the cleavage of a-D-glucopyranosyl fluoride. J. Am. Chem. Soc. 1991, 113, 7958-7963.

8. Huang, X.; Surry, C.; Hiebert, T.; Bennet, A. J., Hydrolysis of (2-Deoxy-beta-Dglucopyranosyl)pyridinium Salts. J. Am. Chem. Soc. 1995, 117, 10614-10621.

9. BeMiller, J. N., Acid-catalyzed hydrolysis of glycosides. Adv. Carbohydr. Chem. 1967, $22,25-108$.

10. Bunton, C. A.; Lewis, T. A.; Llewellyn, D. R.; Vernon, C. A., Mechanisms of reactions in the sugar series. Part I. The acid-catalysed hydrolysis of $\alpha$ - and $\beta$-methyl and $\alpha$ - and $\beta$-phenyl D-glucopyranosides. J. Chem. Soc. 1955, 4419-4423.

11. Overend, W. G.; Rees, C. W.; Sequeira, J. S., 675. Reactions at position 1 of carbohydrates. Part III. The acid-catalysed hydrolysis of glycosides. J. Chem. Soc. 1962, 34293440 .

12. Nath, R. L.; Rydon, H. N., The influence of structure on the hydrolysis of substituted phenyl $\beta$-d-glucosides by emulsin. Biochem. J. 1954, 57, 1-10.

13. Hall, A. N.; Hollingshead, S.; Rydon, H. N., The acid and alkaline hydrolysis of some substituted phenyl alpha-D-glucosides. J. Chem. Soc. 1961, 4290-4295.

14. Wolfenden, R.; Lu, X.; Young, G., Spontaneous hydrolysis of glycosides. J. Am. Chem. Soc. 1998, 120, 6814-6815.

15. Namchuk, M. N.; McCarter, J. D.; Becalski, A.; Andrews, T.; Withers, S. G., The Role of Sugar Substituents in Glycoside Hydrolysis. J. Am. Chem. Soc. 2000, 122, 1270-1277.

16. Ballou, C. E., Alkali-Sensitive Glycosides. Adv. Carbohydr. Chem. 1954, 9, 59-95.

17. Koehler, L. H.; Hudson, C. S., Some Reactions of the 2,4,6-Tribromophenyl $\beta$-DPyranosides of Glucose and Xylose. J. Am. Chem. Soc. 1950, 72, 981-983.

18. McCloskey, C. M.; Coleman, G. H., A proposed inversion mechanism for the formation of levoglucosan from phenyl $\beta$-D-glucoside and trimethylglucosylammonium compounds. $J$. Org. Chem. 1945, 10, 184-193.

19. Gasman, R. C.; Johnson, D. C., C-2 Oxyanion Participation in the Base-Catalyzed Cleavage of $\mathrm{p}$-Nitrophenyl $\beta$-D-Galactopyranoside and p-Nitrophenyl $\alpha$-D-Mannopyranoside. J. Org. Chem. 1966, 31, 1830-1838.

20. Speciale, G.; Farren-Dai, M.; Shidmoossavee, F. S.; Williams, S. J.; Bennet, A. J., C2-Oxyanion neighboring group participation: Transition state structure for the hydroxide- 
promoted hydrolysis of 4-nitrophenyl $\alpha$-D-mannopyranoside. J. Am. Chem. Soc. 2016, 138, 14012-14019.

21. Chan, J.; Sannikova, N.; Tang, A.; Bennet, A. J., Transition-State Structure for the Quintessential $S_{\mathrm{N}} 2$ Reaction of a Carbohydrate: Reaction of $\alpha$-Glucopyranosyl Fluoride with Azide Ion in Water. J. Am. Chem. Soc. 2014, 136, 12225-12228.

22. Schowen, R. L., Mechanistic deductions from solvent isotope effects. Progress Phys. Org. Chem. 1972, 9, 275-332.

23. Venkatasubban, K. S.; Schowen, R. L., The proton inventory technique. CRC Crit. Rev. Biochem. 1984, 17, 1-44.

24. Bennet, A. J.; Sinnott, M. L., Complete kinetic isotope effect description of transition states for acid-catalyzed hydrolyses of methyl .alpha.- and .beta.-glucopyranosides. J. Am. Chem. Soc. 1986, 108, 7287-7294.

25. Dess, D.; Kleine, H. P.; Weinberg, D. V.; Kaufman, R. J.; Sidhu, R. S., Phase-Transfer Catalyzed Synthesis of Acetylated Aryl $\beta$-D-Glucopyranosides and Aryl $\beta$-DGalactopyranosides. Synthesis 1981, 1981, 883-885.

26. Heightman, T. D.; Vasella, A. T., Recent insights into inhibition, structure and mechanism of configuration retaining glycosidases. Angew. Chem. Int. Ed. 1999, 38, 750-770. 
Graphical abstract

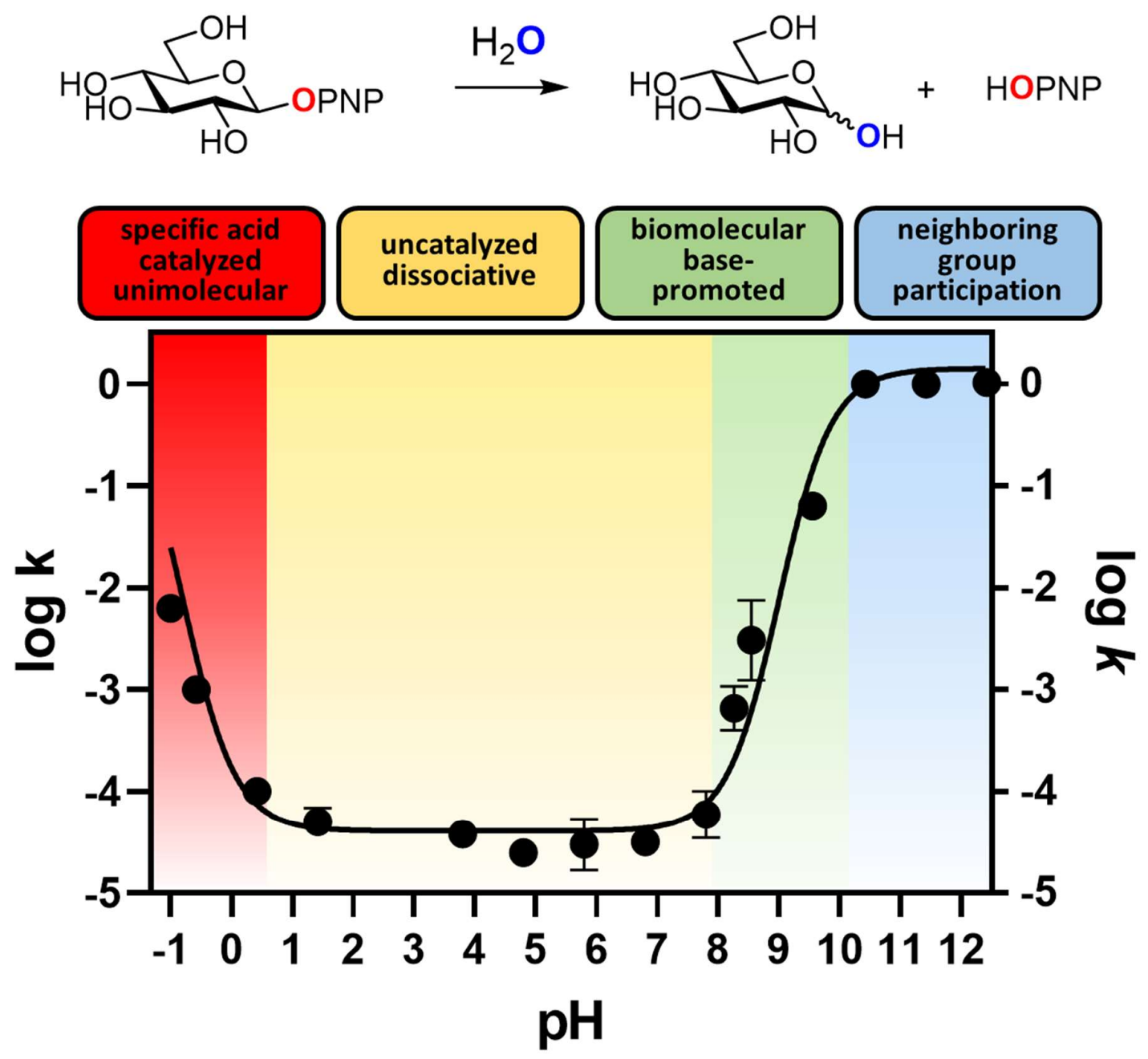

